Western University

Scholarship@Western

2019

Relationship between body image and physical functioning following rehabilitation for lower-limb amputation

Jessica Desrochers

Courtney Frengopoulos

Michael W.C. Payne

Ricardo Viana

Susan W. Hunter

Follow this and additional works at: https://ir.lib.uwo.ca/ptpub

Part of the Physical Therapy Commons 


\section{Relationship between body image and physical functioning following rehabilitation for lower limb amputation}

Jessica Desrochers BHSc ${ }^{1}$; Courtney Frengopoulos $\mathrm{MSc}^{2 ;}$ Michael WC Payne $\mathrm{MD}^{3}$; Ricardo Viana $\mathrm{MD}^{3}$; Susan W Hunter $\mathrm{PhD}^{3,4}$

1. School of Health Studies, University of Western Ontario, London, ON; 2. Faculty of Health \& Rehabilitation Sciences, University of Western Ontario, London, ON; 3. Department of Physical Medicine \& Rehabilitation, Schulich School of Medicine and Dentistry, University of Western Ontario, London, ON; 4. School of Physical Therapy, University of Western Ontario, London, ON.

Running title: Body image and mobility in lower extremity amputees

\section{Corresponding author:}

Dr. Susan W Hunter

University of Western Ontario

School of Physical Therapy

Room 1588, Elborn College

1201 Western Road, London, Ontario

Email: susan.hunter@uwo.ca

Telephone: 519-661-2111 ext88845

Funding: This work was supported by the St. Joseph's Foundation Cognitive Vitality and Brain Health Seed Funding Opportunity. The funding body had no involvement in the conduct of the study.

Conflict of interest: None to report. 


\section{Relationship between body image and physical functioning following rehabilitation for lower limb amputation}

\section{ABSTRACT}

Objectives: To evaluate change in body image and the association between body image at discharge and mobility 4 months post rehabilitation.

Methods: Prospective cohort of consecutive admissions to inpatient prosthetic rehabilitation. Adults $\geq 50$ years undergoing rehabilitation for first major lower limb amputation were assessed at discharge and 4 months post-rehabilitation. Paired t-tests compared total Amputee Body Image Scale (ABIS), gait velocity, and L Test scores between discharge (T1) and 4 months (T2). Multivariable linear regression assessed relationship between ABIS scores and mobility. Results: Nineteen participants completed assessments (mean age $=60.86 \pm 6.85$ years; 63.20\% males). Body image changed from T1 $(43.58 \pm 7.83)$ to T2 $(48.26 \pm 12.21)$, but was not statistically significant $(\mathrm{p}=0.063)$. Mobility significantly improved at T2. ABIS scores at T1 were not associated with mobility at T2.

Conclusions: Mobility improved after discharge, but was not related to body image at T1. Additional research on the impact of body image perception on patient outcomes after rehabilitation is needed.

Keywords: amputation, body image, lower extremity, rehabilitation 


\section{INTRODUCTION}

The loss of a limb has significant physical and psychological consequences for an individual (Coffey et al., 2012). In Canada, diabetes and peripheral arterial disease account for over $80 \%$ of lower limb amputations (LLA)(Kayassi et al., 2016). Rates of acquired LLA are expected to increase as diabetes prevalence is forecast to rise (Pelletier et al., 2011). This highlights the need for greater understanding of the psychological processes associated with limb loss (Pelletier et al., 2011).

The rehabilitation process places physical, cognitive, and psychosocial demands on individuals. Rehabilitation goals following an LLA include restoring independent mobility and enhancing quality of life (QOL) (Schaffalitzky et al., 2011). The most important contributor to QOL is successful mobility (Suckow et al., 2015). The initial months post-discharge are important for evaluating factors that influence mobility gains as mobility improves until 6 months following rehabilitation and then plateaus (Fortington et al., 2013).

Body image also influences QOL after an LLA (Holzer et al., 2014). Body image is the mental perception a person creates of their physical self (Breakey, 1997a). It is a dynamic concept affected by internal perceptions, social interactions and external surroundings (Price, 2016). Disturbance may stem from social values praising vitality, physical appearance, and fitness (Holzer et al., 2014).

Individuals with an LLA due to diabetes have high body image concerns, lower physical QOL and higher rates of depression (Mcdonald et al., 2014). Yet, use of a prosthesis improves mobility and acceptance of the cosmetic aspects of an amputation (Fisher and Hanspal, 1998; Murray and Fox, 2002). Despite this, replacing an amputated limb with a prosthetic device does not resolve body image disturbance (Mayer et al., 2008). 
Body image perception also has the potential to impact motivation and social engagement following amputation. Male veterans with an LLA who were self-conscious of their prosthetic leg demonstrated low acceptance of their appearance, leading to less participation in previously enjoyed activities (Littman et al., 2017). A reduction in participation could directly impact functional mobility gains. Exploring the relationship between body image perception and mobility is necessary to optimize the early post-rehabilitation phase.

The aims of this study among older adults with a unilateral LLA were: 1) evaluate body image change between discharge and four months post-rehabilitation and 2) to evaluate the association between body image at discharge on mobility at four months after inpatient rehabilitation.

\section{MATERIALS AND METHODS}

\section{Study Sample}

This is a prospective cohort study of older adults attending the Amputee Rehabilitation Program at Parkwood Institute in London, Ontario, Canada between April 2016 and August 2017. Admission criteria for the 6-bed inpatient rehabilitation program were: $\geq 18$ years with a major LLA, have identifiable rehabilitation goals, medically stable, and mentally and physically ready to enter the rehabilitation program. Eligibility for the study were $\geq 50$ years, functional use of English, rehabilitation for first major LLA and can walk 10 meters with prosthesis without the assistance of another person, though use of mobility aid is allowed. Exclusion criteria were neurological problems with motor deficits (e.g., stroke) or severe medical conditions that that would compromise the person's ability to safely complete the walking assessments. Assessments occurred within 48 hours of discharge (T1) from inpatient rehabilitation. Four months follow-up (T2) assessment occurred at a regularly scheduled medical appointment. 
The research protocol was approved by the University of Western Ontario Research Ethics Board for Health Sciences Research and the Clinical Resources Impact Committee at Lawson Research Institute in London, Ontario, Canada. All subjects provided informed written consent.

\section{Outcome Measures}

Demographic information collected included: sex, age, height, weight, years of education, comorbidities, number of medications at the time of discharge, amputation level, employment status, living situation, and etiology of amputation. Assessments were completed by one research assistant experienced in the evaluation of people with an LLA. Amputee Body Image Scale (ABIS)

The ABIS is a 20-item questionnaire that quantifies body image with and without a prosthesis (Breakey, 1997b). Each question is scored on a 5-point Likert scale from 1 (none of the time) to 5 (all of the time). Scores range from 20-100; higher scores indicate higher body image disturbance (Breakley, 1997b). This scale has good reliability (Gallagher, 2007).

\section{Gait Velocity}

Gait velocity was measured using the GAITRite ® System; an instrumented walkway measuring 6 meters by 0.64 meters. Individuals walked at their usual pace. To ensure that only steady state walking was captured during the assessments one-meter acceleration and deceleration zones were provided beyond the ends of the mat. Information from these zones was not picked up by the system and therefore was not included in calculations of gait parameters. If a person was using a mobility aid, the gait assessment was performed with their usual aid.

\section{Test of Functional Mobility (L Test)}


Performance on the L Test represents minimum requirements for household mobility (Deathe and Miller, 2005). Participants completed the test at their usual pace and were timed to the nearest hundredth of a second. Lower scores indicate increased walking capability (Deathe and Miller, 2005). The minimal clinically important difference for the L Test is 4.5 seconds (Rushton, Miller and Deathe, 2015).

\section{Data Analysis}

Descriptive statistics analyzed participants' demographics. Participants who completed and did not complete the study were compared with Wilcoxan Ranked Sign Test and Chi square. Paired t tests evaluated change in body image between T1 and T2. Multivariable linear regression modeling investigated association between ABIS scores at T1 on mobility at T2. Variables for confounding control were selected based on the literature. Significance level was set to $\mathrm{p}<0.05$. Analysis was performed with SPSS (V24.0, SPSS Inc., Chicago, IL).

\section{RESULTS}

\section{Demographics and Clinical Characteristics}

Thirty participants enrolled in the study, with 19 completing assessments at T1 and T2. Of the 11 participants not included, three did not complete the ABIS at T1 and eight did not have complete data at T2. Individuals with complete data differed from those with incomplete data; representing a healthier and higher functioning group though the differences were not statistically significant.

The participants were primarily male $(63.20 \%)$ with a mean age of $60.86 \pm 6.85$ years. Comorbidities were common in this cohort, especially vascular morbidities such as hypertension (63.20\%), diabetes (68.42\%), dyslipidemia (42.10\%).(Table 1) All participants used a mobility aid at discharge from rehabilitation and only $73.7 \%$ used a mobility aid for ambulating both 
indoors and outdoors at the 4-months follow-up. Type of mobility aid used changed between discharge and the follow-up visit.

\section{Amputee Body Image Scale}

The mean total ABIS score increased from T1 to T2. (Table 2) Scores indicate a low to moderate level of dissatisfaction (Table 3). Fourteen items demonstrated a decrease in body image perception at $\mathrm{T} 2$.

\section{Relationship Between Body Image at Discharge and Physical Functioning at Four Months}

Mobility scores significantly improved from T1 to T2 (Table 2). The change in the L Test exceeded the minimal clinically important difference. In multivariable linear regression, T1 ABIS scores were not significantly related to L Test or gait velocity at T2 (See Table 4).

\section{DISCUSSION}

This is the first study to demonstrate that body image perception does not influence changes in physical functioning between discharge and four months following rehabilitation. Although mobility did significantly improve, it was not influenced by body image perception.

Zidarov et al. also found no significant changes in ABIS scores between discharge and follow-up (Zidarov, Swaine and Gauthier-Gagnon, 2009). It may take as long as 18 months for body image perception following amputation to change (Breakey, 1997b; Norris et al., 1998; Horgan and Maclachlan, 2009). Our study was conducted within this 18-months transition period, so a lack of change in body image perception prior to the stabilization point suggests that additional longitudinal studies are needed.

Increased physical activity performed regularly by individuals with a unilateral LLA leads to an improved body image perception, highlighting the importance of activity to promote positive body image (Holzer et al., 2014). When physical functioning scores stabilize after 6 
months, patients become concerned with psychosocial issues such as depression, anxiety, problems with relationships and body image (Fortington et al., 2013). This suggests that a new normal for physical abilities, indicated by a plateau in function, causes psychosocial concerns to become more prominent.

Our findings were limited by several factors. Only 19 of the originally recruited participants had complete data at follow-up, therefore the results cannot be generalized to all adults with an LLA. Individuals with complete data represented a healthier cohort, which may have biased results towards the null. Another limitation is that there is no value in the literature for the minimal clinically important difference in the ABIS. Future studies should investigate body image perception using larger sample sizes, due to the high dropout rate possible in this population. However, the participants originally recruited were consecutive admissions, so were representative of the population seen at our facility.

\section{CONCLUSIONS}

Body image perceptions changed between discharge and four months post-rehabilitation among included older adults with a unilateral LLA, but it was not statistically significant. Significant improvements in mobility were seen, though these were not related to body image perception. These findings reinforce the need for additional research on psychological adjustment after limb amputation and its implications on functioning. 


\section{References}

Breakey, J. W. (1997a) 'Body Image: The Inner Mirror', Journal of Prosthetics and Orthotics, 9(3), pp. 107-112. doi: 10.1097/00008526-199700930-00004.

Breakey, J. W. (1997b) 'Body image: The lower-limb amputee', Journal of Prosthetics and Orthotics, 9(2), pp. 58-66. doi: 10.1097/00008526-199700920-00005.

Coffey, L., O’Keeffe, F., Gallagher, P., Desmond, D. and Lombard-Vance, R. (2012) 'Cognitive functioning in persons with lower limb amputations: a review', Disability and Rehabilitation, 34(23), pp. 1950-1964. doi: 10.3109/09638288.2012.667190.

Deathe, A. B. and Miller, W. C. (2005) 'The L test of Functional Mobility: measurement properties of a modified version of the Timed "Up \& Go" Test designed for people with lowerlimb amputations', Physical Therapy, 85(7), pp. 626-635.

Fisher, K. and Hanspal, R. (1998) 'Body image and patients with amputations: does the prosthesis maintain the balance?', International Journal of Rehabilitation Research, 21, pp. 355363.

Fortington, L. V., Dijkstra, P. U., Bosmans, J. C., Post, W. J. and Geertzen, J. H. B. (2013)

'Change in health-related quality of life in the first 18 months after lower limb amputation: A prospective, longitudinal study', Journal of Rehabilitation Medicine, 45(6), pp. 587-594. doi: 10.2340/16501977-1146.

Holzer, L. A., Sevelda, F., Fraberger, G., Bluder, O., Kickinger, W. and Holzer, G. (2014) 'Body image and self-esteem in lower-limb amputees', PLOS ONE, 9(3). doi:

10.1371/journal.pone.0092943.

Horgan, O. and Maclachlan, M. (2009) 'Psychosocial adjustment to lower-limb amputation: A review Psychosocial adjustment to lower-limb amputation: A review', Disability and 
Rehabilitation, 26(14/15), pp. 837-850. doi: 10.1080/09638280410001708869.

Kayassi, A., de Mestral, C., Forbes, T. L. and Roche-nagle, G. (2016) 'A Canadian populationbased description of the indications for lower-extremity amputations and outcomes', Canadian Journal of Surgery, 59(2), pp. 99-106. doi: 10.1503/cjs.013115.

Littman, A. J., Bouldin, E. D. and Haselkorn, J. K. (2017) 'This is your new normal: A qualitative study of barriers and facilitators to physical activity in Veterans with lower extremity loss', Disability and Health Journal, 10, pp. 600-606. doi: 10.1016/j.dhjo.2017.03.004.

Mayer, A., Kudar, K., Bretz, K. and Tihanyi, J. (2008) 'Body schema and body awareness of amputees', Prosthetics and Orthotics International, 32(3), pp. 363-382. doi:

10.1080/03093640802024971.

Mcdonald, S., Sharpe, L. and Blaszczynski, A. (2014) 'The psychosocial impact associated with diabetes-related amputation', Diabetic Medicine, 31, pp. 1424-1430. doi: 10.1111/dme.12474. Murray, C. D. and Fox, J. (2002) 'Body image and prosthesis satisfaction in the lower limb amputee', Disability and Rehabilitation, 24(17), pp. 925-931. doi: 10.1080/09638280210150014.

Norris, J., Kunes-Connell, M. and Spelic, S. S. (1998) 'A grounded theory of reimaging', Advances in Nursing Science, 20(3), pp. 1-12. doi: 10.1097/00012272-199803000-00003. Pelletier, C., Dai, S., Roberts, K. C., Bienek, A., Onysko, J. and Pelletier, L. (2011) 'Report summary. Diabetes in Canada: facts and figures from a public health perspective', Chronic Diseases and Injuries in Canada; Ottawa. Public Health Agency of Canada, 33(1), pp. 53-54. Available at: http://vr2pk9sx9w.search.serialssolutions.com/?ctx_ver=Z39.882004\&ctx_enc=info\%3Aofi\%2Fenc\%3AUTF8\&rfr_id=info\%3Asid\%2Fsummon.serialssolutions.com\&rft_val_fmt=info\%3Aofi\%2Ffmt $\% 3 \mathrm{~A}$ 
kev\%3Amtx\%3Ajournal\&rft.genre=article\&rft.atitle=Report+summary.+Diabetes+in .

Price, B. (2016) 'Enabling patients to manage altered body image', Nursing Standard, 31(1618), pp. 60-71. doi: 10.7748/ns.2016.e10576.

Rushton, P. W., Miller, W. C. and Deathe, A. B. (2015) 'Minimal clinically important difference of the L Test for individuals with lower limb amputation : A pilot study', Prosthetics and Orthotics International39, 39(6), pp. 470-476. doi: 10.1177/0309364614545418.

Schaffalitzky, E., Gallagher, P., Maclachlan, M. and Ryall, N. (2011) 'Understanding the benefits of prosthetic prescription: exploring the experiences of practitioners and lower limb prosthetic users', Disability and Rehabilitation, 33(15-16), pp. 1314-1323. Available at: https://www-tandfonlinecom.proxy.lib.ul.ie/doi/pdf/10.3109/09638288.2010.529234?needAccess=true. Suckow, B. D., Goodney, P. P., Nolan, B. W., Veeraswamy, R. K., Gallagher, P., Cronenwett, J. L. and Kraiss, L. W. (2015) 'Domains that determine quality of life in vascular amputees', Annals of Vascular Surgery. Elsevier Inc., 29(4), pp. 722-730. doi: 10.1016/j.avsg.2014.12.005. Zidarov, D., Swaine, B. and Gauthier-Gagnon, C. (2009) 'Quality of Life of Persons With Lower-Limb Amputation During Rehabilitation and at 3-Month Follow-Up', Archives of Physical Medicine and Rehabilitation, 90(4), pp. 634-645. doi: 10.1016/j.apmr.2008.11.003. 
Table 1: Demographic and clinical characteristics of a prospective cohort study of patients with a unilateral lower limb amputation at discharge from prosthetic rehabilitation. $(n=19)$.

\begin{tabular}{|c|c|c|c|}
\hline & \multicolumn{2}{|c|}{ Mean \pm SD } & \multirow[b]{2}{*}{ p-value* } \\
\hline Variable & $\begin{array}{l}\text { Participants who } \\
\text { completed study } \\
(n=19)\end{array}$ & $\begin{array}{l}\text { Participants who } \\
\text { did not complete } \\
\text { the study }(n=11)\end{array}$ & \\
\hline Age (years) & $60.9 \pm 6.9$ & $67.7 \pm 10.5$ & 0.450 \\
\hline Body Mass Index $\left(\mathrm{kg} / \mathrm{m}^{2}\right)$ & $28.3 \pm 5.6$ & $28.4 \pm 8.1$ & 0.450 \\
\hline Sex (\% male $)$ & $63.2 \%$ & $54.5 \%$ & 0.212 \\
\hline Amputation Level (\% trans-tibial) & $84.2 \%$ & $72.7 \%$ & 0.556 \\
\hline Years of Education & $12.8 \pm 2.1$ & $13.0 \pm 3.6$ & 0.696 \\
\hline Number of Comorbidities & $5.3 \pm 2.2$ & $6.2 \pm 2.8$ & 0.417 \\
\hline Number of Medications (initial) & $10.1 \pm 4.1$ & $11.1 \pm 6.7$ & 0.454 \\
\hline \multicolumn{4}{|l|}{ Primary Etiology of Amputation } \\
\hline Diabetes & $63.2 \%$ & $63.6 \%$ & 0.457 \\
\hline Peripheral Vascular Disease (PVD) & $10.5 \%$ & $27.3 \%$ & \\
\hline
\end{tabular}




\begin{tabular}{|c|c|c|c|}
\hline Diabetes and PVD & $5.3 \%$ & $9.1 \%$ & \\
\hline Cancer & $5.3 \%$ & $0 \%$ & \\
\hline Infection & $15.8 \%$ & $0 \%$ & \\
\hline Mobility Aid Use at Discharge from Rehabilitation & $100 \%$ & $100 \%$ & 1 \\
\hline \multicolumn{4}{|l|}{ Type of Mobility Use at Discharge from Rehabilitation } \\
\hline Single standard cane & $10.5 \%$ & $18.2 \%$ & 0.605 \\
\hline Two standard canes & $10.5 \%$ & $9.1 \%$ & \\
\hline Forearm crutches & $5.3 \%$ & $0 \%$ & \\
\hline 2-Wheeled Walker & $0 \%$ & $9.1 \%$ & \\
\hline 4-Wheeled Walker & $73.7 \%$ & $63.6 \%$ & \\
\hline Mobility Aid Use at 4-months Follow-up & $73.7 \%$ & & \\
\hline \multicolumn{4}{|l|}{ Type of Mobility Aid Use at 4-months Follow-up } \\
\hline Single standard cane & $21.1 \%$ & & \\
\hline Two standard canes & $5.3 \%$ & & \\
\hline Standard walker & $26.3 \%$ & & \\
\hline 2-Wheeled Walker & $10.5 \%$ & & \\
\hline
\end{tabular}




\begin{tabular}{|c|c|c|c|}
\hline 4-Wheeled Walker & $14.2 \%$ & & \\
\hline \multicolumn{4}{|l|}{ Employment Status } \\
\hline Employed (Full-time) & $21.1 \%$ & $18.2 \%$ & 0.261 \\
\hline Employed (Part-time) & $0 \%$ & $18.2 \%$ & \\
\hline Unemployed & $21.1 \%$ & $18.2 \%$ & \\
\hline Retired & $42.1 \%$ & $45.4 \%$ & \\
\hline On Long-term Disability & $15.8 \%$ & $0 \%$ & \\
\hline \multicolumn{4}{|l|}{ Living Situation } \\
\hline 2-storey house & $42.1 \%$ & $36.4 \%$ & 0.524 \\
\hline Bungalow & $31.6 \%$ & $18.2 \%$ & \\
\hline Apartment & $26.3 \%$ & $45.4 \%$ & \\
\hline
\end{tabular}

*Wilcoxan Rank Sign test performed for comparison of two means and chi square was used to compare proportions. 
Table 2. Scores on outcome measures for older adults with a unilateral lower limb amputation at discharge (T1) and 4 months after (T2) an inpatient prosthetic rehabilitation program.

\begin{tabular}{|c|c|c|c|}
\hline \multirow{2}{*}{ Variable } & \multicolumn{2}{|c|}{ Mean \pm SD } & \multirow{2}{*}{ p-value } \\
\cline { 2 - 4 } & Discharge (T1) & 4 Month (T2) & \\
\hline L Test (sec) & $72.40 \pm 44.62$ & $48.79 \pm 30.02$ & $0.002 *$ \\
\hline Gait velocity (cm/sec) & $52.51 \pm 26.46$ & $69.61 \pm 26.11$ & $<0.001^{*}$ \\
\hline ABIS Score & $43.58 \pm 7.83$ & $48.26 \pm 12.20$ & 0.063 \\
\hline
\end{tabular}

* Statistically significant difference between scores at discharge and 4 months post-discharge;

ABIS, Amputee Body Image Scale 
Table 3. Amputee Body Image Scale scores for older adults with a unilateral lower limb amputation at discharge (T1) and 4 months after (T2) an inpatient prosthetic rehabilitation program.

\begin{tabular}{|c|c|c|}
\hline Question & T1 & T2 \\
\hline 2) I avoid wearing shorts in public because my prosthesis would be seen. & $1.74 \pm 1.28$ & $2.11 \pm 1.60$ \\
\hline $\begin{array}{l}\text { 4) It concerns me that the loss of my limb impairs my body's functional capabilities in various activities of } \\
\text { daily living. }\end{array}$ & $2.21 \pm 0.92$ & $3.00 \pm 1.25$ \\
\hline 5) I avoid looking into a full-length mirror in order not to see my prosthesis. & $1.16 \pm 0.50$ & $1.58 \pm 1.17$ \\
\hline 6) Because I am an amputee, I feel anxious about my physical appearance on a daily basis & $1.79 \pm 0.92$ & $1.79 \pm 1.08$ \\
\hline 9) It concerns me that the loss of my limb impairs my ability to protect myself from harm. & $2.26 \pm 1.33$ & $2.47 \pm 1.02$ \\
\hline $\begin{array}{l}\text { 10) When I am not wearing my prosthesis, I avoid situations where my physical appearance can be } \\
\text { evaluated by others (e.g., avoid social situations, swimming pool or beach activities, physical intimacy). }\end{array}$ & $1.21 \pm 0.42$ & $1.74 \pm 1.20$ \\
\hline 11) The loss of my limb makes me think of myself as disabled. & $2.32 \pm 1.29$ & $2.37 \pm 1.34$ \\
\hline
\end{tabular}




\begin{tabular}{|c|c|c|}
\hline 12) I like my physical appearance when not wearing my prosthesis. & $2.89 \pm 1.63$ & $3.37 \pm 1.30$ \\
\hline 13) When I am walking, people notice my limp. & $2.74 \pm 1.66$ & $2.74 \pm 1.33$ \\
\hline $\begin{array}{l}\text { 14) When I am wearing my prosthesis, I avoid situations where my physical appearance can be evaluated } \\
\text { by others (e.g., avoid any social situations, swimming pool or beach activities, physical intimacy). }\end{array}$ & $1.42 \pm 0.69$ & $2.05 \pm 1.35$ \\
\hline 15) People treat me as disabled. & $3.00 \pm 1.29$ & $2.37 \pm 1.12$ \\
\hline 16) I like the appearance of my stump anatomy. & $3.42 \pm 1.81$ & $3.26 \pm 1.45$ \\
\hline 17) I wear baggy clothing in an attempt to hide my prosthesis. & $1.47 \pm 0.84$ & $1.95 \pm 1.13$ \\
\hline 18) I feel I must have four normal limbs to be physically attractive. & $1.32 \pm 0.75$ & $2.21 \pm 1.23$ \\
\hline $\begin{array}{l}\text { 19) It is important the size of my prosthesis and remaining anatomy of the affected limb are the same as } \\
\text { the other limb. }\end{array}$ & $2.21 \pm 1.65$ & $2.32 \pm 1.57$ \\
\hline 20) I avoid looking into a full-length mirror in order not to see my stump anatomy. & $1.26 \pm 0.73$ & $1.68 \pm 1.29$ \\
\hline
\end{tabular}


Table 4: Association between the mean Amputee Body Image Scale (ABIS) scores at discharge (T1), and the L Test and gait velocity scores 4 months after (T2) an inpatient prosthetic rehabilitation program for older adults with a unilateral lower limb amputation.

\begin{tabular}{|c|c|c|c|c|}
\hline Variable & $\begin{array}{c}\text { Unadjusted } \boldsymbol{\beta} \\
(\mathbf{9 5 \%} \mathbf{C I})\end{array}$ & p-value & $\begin{array}{c}\text { Adjusted } \boldsymbol{\beta}^{*} \\
(\mathbf{9 5 \%} \mathbf{C I})\end{array}$ & p-value \\
\hline Outcome= Mean L Test score at T2 & -1.24 & 0.061 & -0.95 & 0.142 \\
\hline Mean total ABIS score at T1 & $(-2.54-0.07)$ & & $(-2.25-0.36)$ & \\
\hline Outcome= Mean gait velocity score at T2 & & -0.04 & 0.939 \\
\hline Mean total ABIS score at T1 & 0.61 & 0.455 & $(-1.22-1.14)$ & \\
\hline
\end{tabular}

* Adjusted for age, sex and etiology; statistical significance set at $\mathrm{p}<.05$. 